\title{
Da vida à morte à vida: a linguagem é a ponte. Reflexões acerca do ato de escrever
}

\author{
Maria Rosa Rodrigues Martins de Camargo*
}

Resumo: Este trabalho traz reflexões acerca do ato de escrever, numa perspectiva de invenção contextualizada em situações de fronteira entre a vida e a morte, configurando potente exercício de si, por um grupo particular de escritores. Foram utilizadas como material cartas publicadas em livro, escritas por pessoas condenadas à morte, vítimas do nazismo; nelas, percebe-se a consciência da morte iminente e o fato comprovado. O objetivo é aprofundar estudos sobre o ato de escrever, na perspectiva de sua metamorfose e de quem escreve e/ou lê, fundada na autonarração e autointerpretação. Este artigo ancora-se em estudos da linguagem e em reflexões do ato de escrever levantados por quem escreve, que delineia-se pelos assuntos corriqueiros, linguagem singela, quase pura de intenções e um incessante desejo de ser lembrado, pondo em foco um exercício de si. Pela leitura estabelecese um vínculo fronteiriço e indissolúvel entre a vida, a morte e a vida, trazida pelas formas vivas da linguagem.

Palavras-chave: Linguagem. Escrita. Leitura. Experiência.

\section{From life to death to life. The language is the bridge. Reflections about the acto of writing}

\begin{abstract}
This paper presents reflections on the act of writing, in its perspective of invention, contextualized in situations in the border between life and death, setting a powerful exercise about itself by a particular group of writers. It was used as material letters compiled and published in book form, written by people

* Doutora em Educação pela Universidade Estadual de Campinas (UNICAMP). Professora de Didática no Curso de Ciências Biológicas e no Programa de PósGraduação em Educação, no Instituto de Biociências da Universidade Estadual Paulista "Júlio de Mesquita Filho". Livre docente em Didática pela Universidade Estadual Paulista “Júlio de Mesquita Filho”.E-mail: mrosamc@rc.unesp.br
\end{abstract}


sentenced to death, victims of nazism; on it is the perception of the awareness of imminent death and the proven fact. The objectif is go further in the studies of the act of writing, in the perspective of its metamorphosis and of who writes and/or reads, estabilished on self narration and self interpretation. This article anchors in language studies and reflections on the act of writing raised by the writer, placed by trivial matters, simple language, almost pure intentions and an incessant desire to be remembered, focusing on an exercise of itself. By reading, it seems to set up a bond and indissoluble border between life and death and life brought by the living forms of language.

Keywords: Language. Writing. Reading. Experience.

\section{De la vida a la muerte a la vida: el lenguajees el puente. Reflexiones acerca del acto de escribir}

Resumen: Este trabajo trae reflexiones acerca del acto de escribir, enuna perspectiva de invención, contextualizada en situaciones de frontera entre la vida yla muerte, configurando un potente ejercicio de sí mismo, por un grupo particular de escritores. Material: cartas publicadas enlibro, escritas por personas condenadas a muerte, víctimas del nazismo; enellas, se notala conciencia de la muerte inminente y el hecho comprobado. Objetivo: profundizar los estudios sobre el acto de escribir, en la perspectiva de su metamorfosis y de quien escribey/o lee, basada en la auto-narracióny auto-interpretación. Análisis: se fundamenta en estudios del lenguajey en reflexiones del acto de escribir levantados por quien escribe, que se delineanpor los asuntos cotidianos, lenguaje simple, casi puro de intenciones y un incesante deseo de ser recordado, poniendo en foco un ejercicio de sí mismo. Por la lectura se establece un vínculo fronterizo e indisoluble entre la vida, la muerte y la vida, traída por las formas vivas del lenguaje.

Palabras clave: Lenguaje. Escritura. Lectura. Experiencia.

Ninguno de vosotros quedará para contarlo, pero incluso si alguno lograra escapar, el mundo no le creería...

Primo Levi no escribe para hacer literatura, sino para contar, para remontar la constatación de Benjamín según la cual los hombres vuelven mudos del horror, sin nada que contar. Y eso es el problema: cómo 
alcanzar a contar aquello que pertenece a la intimidad más abismal de la vida inenarrable, ese oscuro temor que nos habita.

(MOREY, 2007, p. 364-365)

Este trabalho traz reflexões a respeito da linguagem escrita, em sua perspectiva de invenção, contextualizada em situações de fronteira entre a vida e a morte, configurando um potente exercício de si, por um grupo particular de escritores. O objeto material de estudo são as cartas compiladas, selecionadas e publicadas em livro de bolso (1975), escritas por pessoas condenadas à morte, vítimas do nazismo.

Este estudo é um recorte teórico da pesquisa $A$ aventura da escrita por pessoas em salas de EJA como objeto de formação para professores (em EJA): por entre práticas culturais, saberes e linguagens, ${ }^{1}$ que tem como objetivo geral aprofundar estudos sobre o ato de escrever na perspectiva de sua permanente metamorfose e de metamorfose de quem escreve e/ou lê, fundada na autonarração e autointerpretação que podem ser lidas [e interpretadas] nos diversos tipos de material escrito - diários, cartas, folhas soltas, cadernos - que vão desde a escrita literária - na forma de livros publicados - à escrita por pessoas pouco escolarizadas, por exemplo; no âmbito deste artigo, remeto-me às cartas publicadas. $\mathrm{O}$ que norteia para uma perspectiva de transformação, que se efetiva nas práticas da escrita, é pôr o foco no agente principal dessa transformação, que é a pessoa que escreve.

A busca de (outros) referenciais que propiciassem o aprofundamento de reflexões do ato de escrever na relação - intensa e vivida - com o sujeito, com a pessoa que escreve, me pôs em contato com estudos de autoria de Jorge Larrosa inspirando-se, particularmente, em um estudo intitulado Narrativa, identidad y desidentificación (LARROSA, 1996). Ao estudo inspirador fui alinhando-me pelos aportes que se norteiam

1 O Projeto de pesquisa contou com o apoio financeiro do CNPq, Processo 401263/2010-0 com vigência de agosto/2010 a agosto/2012. 
pela e na dinâmica da autointerpretação narrativa entendida como fenômeno de intertextualidade, de polifonia e de políticas do discurso. A este alinhamento fui emparelhando algumas possibilidades a que o objeto de estudo me desafiava, na perspectiva de metamorfose que abriga a interpenetração da linguagem, do ato de escrever, do escrever como experiência.

A narrativa de como se é e de como se vê compõe-se dos muitos textos, aproximando-nos do fenômeno de intertextualidade, ou seja, das muitas histórias que se ouve, que se conta, que se ouve de si mesmo, que se mesclam na efervescência da cultura. Da intertextualidade que interpreto com Walter Benjamin (1985), do que está implicado na leitura da história e das histórias que se entrecruzam para cada pessoa - ser histórico, fazer história, viver a história - e ser dado da história, da pobreza da experiência. E da intertextualidade que busco em Nietzsche (apud LARROSA, 2002) ao abrir-me para ler em direção ao desconhecido.

Decorrente desses ensaios de pensamento, que têm se configurado como busca de entender, perguntas se colocam: de que modo posso recorrer a Nietzsche, com que elementos posso pensar que os textos, neste caso, cartas, escritas por pessoas (condenadas à morte, por exemplo) podem ser chamados à escuta, a partir do que Nietzsche diz e nos sacode quanto ao que é ser leitor? Que tipo de leitor somos quando lemos aquelas cartas? Em Assim falou Zaratustra há uma pista quando o autor diz que as frases ali escritas talvez não sejam compreensíveis porque são a própria vivência (a do autor, nesse caso). Ou em Aurora, quando afirma ser este um livro que diz SIM ao elevado direito e privilégio à existência (NIETZSCHE, 1986). Ou em A gaia ciência (NIETZSCHE, 2002), quando diz que ainda não descobriu outra maneira de se livrar de seus pensamentos, sendo o ato de escrever uma possibilidade de resolver essa necessidade.

Do fenômeno de polifonia, pergunto: que vozes se interpõem nos textos que escrevem os correspondentes condenados à morte? Para quem escrevem? Inclui-se, aí, a possibilidade de um diálogo com o tempo histórico na relação com a diversidade dos espaços em que tais vozes são situadas. 
E tendo em vista o fenômeno de políticas do discurso transito pela história das práticas discursivas; enquanto autonarração, são também uma história social e uma história política (FOUCAULT, 2006).

$\mathrm{O}$ fenômeno de intertextualidade, de polifonia e de políticas do discurso, a meu ver, também abrem perspectivas de aporte na escrita literária, entendendo-se que esta abriga a interpenetração da linguagem, do ato de escrever, do escrever como experiência. Para o autor e para o leitor. Em Nietzsche, como apontado, em Bakhtin (2003) ou em Foucault, encontro material farto nesse sentido. A Bakhtin, ao perguntar-se cómo se resuelve este conflicto entre pensamiento y experiencia viva, entre el mundo del pensamiento en cuyo interior estoy, y el mundo afora de mí mismo, sobre cuya tangente me ubico (BAJTÍN, 1997, p. 148). A Foucault (2006) interessa o que a escrita (e a escrita literária como uma de suas formas maiores) tem de soberana, de inassimilável e de absolutamente livre: seu poder para enfrentar a história, o mundo e o homem, para brilhar fora de seus limites e, desde aí, desde essa distância nunca fechada, pô-los em perigo.

Pouco tem sido localizado, na leitura dos escritos desses autores, que remeta diretamente aos tema de estudos que emergem da pesquisa, seja com relação ao ato de escrever, seja com relação ao ato de escrever por pessoas adultas com pouca escolaridade. Contudo, a modo de ampliação das reflexões teóricas, que possam acrescentar consistência, invenção que possibilite outros modos de interpretar a questão das práticas da escrita (e da leitura), indico que a contribuição desses autores pode estar na busca intensa da relação entre a escrita (o ato de escrever) e a própria existência. Ato de escrever que se constitui, ele próprio, num dos modos de existir. Ato de escrever que se constitui em uma aventura, soberana, que brilha fora dos limites constituídos pelas marcas que definem textos literários, ou textos de analfabetos, ou textos de não analfabetos. Talvez possa ser lembrada também a chamada que Rancière nos faz em $A$ literatura impensável em que argumenta pela "Literatura" como pertencente a essa delimitação e a essa guerra da escrita onde se fazem e se desfazem as 
relações entre a ordem do discurso e a ordem dos estados (1995, p. 27).

Para além das marcas definidoras possíveis, quaisquer que sejam os tipos de textos ou contextualização social e intelectual de seus autores, esta nem é uma preocupação neste momento, o encontro com o livro Cartas de condenados a muerte. Victimas del nazismo (COMAS, 1975) ressoou como um material que extrapola explicações teóricas: não há como passar ilesa por tal leitura. No entanto, uma apresentação do mesmo não somente é necessária, como é um modo de compartilhar leituras... histórias... história... memória... e outros exercícios que remetem à vida, à morte, à vida. A escrita é o tema, sobretudo, o devaneio, o percurso.

\section{Apontamentos sobre o livro e o contexto}

O que chama a atenção, de início, é constatar que o livro não tem autoria, traz o nome do tradutor, o responsável pela seleção - Ramón Comas, que neste texto indica a referência - os responsáveis pela edição - Piero Malavezzi e Giovanni Pirelli, e informa a primeira edição em junho de 1972 (o exemplar que tenho em mãos é a segunda edição, de março de 1975). O texto exposto pela Editorial Laia (que o publica) é sugestivo.

Condenados a muerte. Libro sin autor. Porque la aportación colectiva de quienes firman estas Cartas va infinitamente más allá de la elaboración de unos textos literarios más o menos desgarradores y verídicos. Sus firmas avalan, no un libro, sino un retazo de historia construida al precio de sus vidas - la Resistencia contra el fascismo en los años de la ocupación nazi - historia que nos ha sido legada en lo que tiene de heroica y de vergonzante, y que nos incumbe imperativamente por cuanto también nosotros hemos testigos de este asesinato colectivo (COMAS, 1975, grifos meus contracapa face externa).

Na sequência da leitura, ative-me à nota dos compiladores. Por ela ficamos informados que a seleção das cartas - surgidas de modo copioso - deu-se por inserirem-se contextualmente no movimento designado 
como Resistência, que adquiriu amplitude e características particulares no período compreendido entre 1939 e 1945, em países europeus beligerantes. Informa também que, junto à guerra "oficial", existiu uma outra guerra, chamada "clandestina" ou de "resistência armada" [destaques postos pelo autor] que não seria novidade entre a história dos povos mas que, naqueles anos,

debido a la voluntad de supervivencia y a los ardientes ideales que la animaron, por la consistencia de las fuerzas que se movilizaron y actuaron conjuntamente y por el grado de organización político-militar alcanzado, se convirtió en elemento de importancia extraordinaria y quizás decisiva para el desenvolvimiento de la guerra "oficial" y para las soluciones políticas de posguerra. Es ésta una ulterior justificación de los límites cronológicos y geográficos de esta selección (COMAS, 1975, p. II).

A busca pelo material - as cartas, deu-se pelos mais insólitos caminhos e solicitando as colaborações as mais diversas com algumas indicações do que se buscava. Segundo informam os compiladores, dirigiram-se a

asociaciones de ex resistentes o de deportados políticos y victimas de la persecución, organizaciones políticas y asistenciales, direcciones de archivos, de centros de documentación, de instituciones y bibliotecas especializadas, capellanes de cárcel, miembros de la Resistencia, familiares de caídos, editores, amigos de diferentes países etc. Se solicitó su colaboración para: a) la localización o envío de material impreso que contuviera Cartas o indicaciones útiles para su localización; b) la búsqueda de Cartas inéditas cuando no estaban editadas o cuando resultaba necesario completar las ya publicadas en cuanto a número y características; c) la búsqueda de noticias relativas a los autores de Cartas, a las situaciones y episodios relativos a su experiencia (COMAS, 1975, p. III).

O material juntado foi copioso e proveniente de países diversos, como indica a lista de pessoas e entidades que consta às páginas VI a VIII do livro. 
Sem diferenciar se os autores das cartas - nomeados e com uma breve biografia - tiveram participação ativa ou passiva na Resistência, se militantes ou simpatizantes, o critério de terem sido perseguidos e condenados foi estabelecido para a seleção.

Da apresentação do livro há a destacar o Prefácio de autoria de Thomas Mann. Da leitura das cartas de condenados à morte, o autor nos remete a uma narração de Leon Tolstoi intitulada Divino e humano, escrita em 1905, no último período da vida do grande escritor épico. A narração transcorre nos anos setenta do século XVIII e trata-se da luta entre revolucionários russos e o governo, que alcançava seu ponto culminante. Segundo Mann, Tolstoi descreve com incomparável profundidade os últimos dias de um estudante da Universidade de Odessa, que envolvido - por patriotismo e nobre imprudência - em uma conspiração política, é condenado à forca.

Na narração, escreve Mann, revivemos tudo:

La incapacidad de un ser joven y en pleno desarrollo para comprender el sentido del veredicto que se le comunica, para aceptar la propia aniquilación, para creer que los hombres ejecutarán realmente lo que han decretado en su contra; los reproches que se hace a sí mismo por la desesperación de su pobre madre; y, al mismo tiempo, el orgullo de su propio valor, de la fuerza de carácter de que ha dado prueba al negarse tenazmente a revelar el nombre de la persona de quien ha recibido la dinamita que han hallado en su poder (COMAS, 1975, p. 7.)

Ao puxar o fio da narração, Thomas Mann destaca a grande simpatia e conhecimento da alma humana própria de Tolstoi, que se converte em experiência e surpreende ao se constatar o quanto das intuições suas novamente encontramos nos documentos reais que se publicam neste livro.

Do ponto de vista deste artigo, do que aqui é abordado, para além de serem documentos reais, editados, a tessitura do tema remete a um modo de contemplar a vida, a modo de concretizá-la afirmando-a em cada frase escrita. Mesmo tendo a proximidade da morte como certeza. 


\section{Leitura das cartas}

Como elemento comum nas cartas, encontra-se a consciência da morte iminente e o fato comprovado. A leitura das cartas nos informa que foram dirigidas a familiares (mãe, pai, filho, esposa, avó, tios) ou pessoas do restrito círculo de amizade.

São diversos e recorrentes os temas que podem ser levantados na leitura das cartas: a certeza da morte num curto espaço de tempo e data incerta; o não arrependimento pelo que ocasionou a perseguição e condenação do autor; a afirmação, esperança, quase fé em seu feito para dias melhores, no entanto, sem sombras de apologias a si; um repensar a vida na iminência calma da morte, e outros. Alguns trechos selecionados das cartas, do livro, dão uma ideia desses temas. Muito mais teria a ser dito.

A certeza da morte num curto espaço de tempo e data incerta pode ser lida em trechos da carta que escreve Alfred Schmidt-Sas.

Escribo el lunes 8 de marzo. También han pasado los terribles minutos hacia las 13 horas, cuando vienen a buscar de sus celdas a las victimas para la noche y cuando toda la casa sostiene la respiración, también, por hoy, han transcurrido estos minutos y el día puede registrase como otro día ganado...

21 de marzo de 1943... Mañana será otra vez un día crítico de primer orden, y nadie puede saber si dentro de veinticuatro horas estaré aún en esta celda, si dentro de treinta horas estaré aún vivo.

28 de marzo de 1943. Las doce y media. En este momento cuatro compañeros de martirio han sido sacados de la celda... Así, dos o tres veces por semana, me llevan al borde del abismo, y mientras me esfuerzo en mirar adentro con calma, espero el pequeño empujón que bastará para hacerme caer... (Alfred Schmidt-Sas - de 48 años, maestro de escola elementar - a su esposa) (COMAS, 1975, p. 25). 
O não arrependimento pelo que ocasionou a perseguição e condenação do autor, mesmo que seguido dos pedidos de perdão a quem faz sofrer. Não arriscaria a dizer que é a sinceridade do pedido de perdão o dá a força que essas palavras carregam, na iminência da morte.

10 de noviembre de $1942 \ldots$ Perdóname, querida madre, perdona que haya tenido que ocasionarte este dolor. A menudo he pensado si verdaderamente esto era necesario, si quizá no habría debido obrar de otra manera, pero llego siempre a una misma conclusión: "no podía hacer otra cosa"; desde un principio, mi vida ha estado llena de dolores, de preocupaciones, de necesidades, cuántos sufrimientos en común no tuvimos que suportar en la otra guerra, y, luego las cosas siguieron delante de este modo para toda la vida. (Franz Mittendorfer - de 38 años, peletero, miembro de la juventud Obrera - a su madre) (COMAS, 1975, p. 48).

Com a mesma intensidade, o trecho a seguir é como que uma posição que é alternada entre aquele que escreve e para quem escreve. Quem dá força a quem? Sobretudo poético, ou por ser poético, traz uma afirmação que é de esperança, metaforizada pela força da natureza, que, apesar as intempéries, aguarda o calor que a fará brotar.

Conservad un buen recuerdo de mi, pero no mi compadezcáis. Antes bien, permaneced serenos como yo lo estaré hasta el final. Sed fuertes y no perdáis la fuerza que yo tengo y que me permite no tambalearme y no temer nada. Afuera es primavera. Y en mí, aunque estoy en la cárcel, también hay serenidad, como en la primavera que nos anuncia un verano inminente. $Y$ aunque muchos brotes caerán, quemados por el hielo, desnutridos por la tormenta y por el viento, el árbol seguirá floreciendo. Sabe que está cerca el verano que lo calentará, y el sol y la luz se harán cada vez más fuertes, Y así os saludo, aunque tenga que ser por la última vez, con muchos besos y con una sonrisa. ¡La cabeza alta! Vuestro, Walter. (Walter Kämpf - 23 años, estudiante de química - a sus padres) (COMAS, 1975, p. 59). 
É a afirmação, esperança, quase fé que se marca pelas escolhas, no que acredita como um feito seu para dias melhores, no entanto, sem sombras de apologias a si.

Instruyendo al pueblo ingenuo y, sobre todo, con la lucha. Pero en esta lucha pocos quedan con vida. Ya sabía hace tiempo cómo acabaría. Sabía que podía ser una de sus víctimas, pero, a pesar de ello, no he tenido miedo y me he lanzado al torbellino de esta lucha, y todavía tengo fe en esta lucha. Conocía el destino de todo revolucionario, pero también que sin sacrificios no alcanzaremos nunca nuestro ideal; ... me he encontrado en una encrucijada; un camino era cómodo, bastante fácil de recorrer, pero llevaba a la miseria y al abismo; el otro estaba destrozado, cubierto de espinas, pero llevaba hacia un floreciente futuro para la humanidad. No he vacilado en la elección... (Petar Kirjakov - de 19 años, aprendiz de zapatero - a sus padres) (COMAS, 1975, p. 83).

Um rastro de repensar a vida, com toda a carga do afeto que carrega, é um tema que poderia estar contido em qualquer carta das tantas a que temos notícias, ou acesso, ao longo do tempo; no entanto estas trazem, mais do que um repensar a vida e o afeto, leio-a como uma nesga de luminosidade que acalenta a iminência calma da morte.

Pero a la muerte se le ha quitado toda su amargura, no la tristeza, naturalmente, ¿pero, no es ésta casi dulce? Precisamente ahora lo siento intensamente, ahora que, por una indefinible y profunda unión contigo, vuelvo a encontrar el camino hacia las palabras, las ideas. ¿De dónde nos vendrá esto que con mágica fuerza afecta nuestros ánimos y los une? ¿por qué no mana siempre esta fuente? (De Alfred Schmidt-Sas a su esposa) (COMAS, 1975, p. 25).

Y ahora te deseo un buen día con los abuelos y seguramente con Harold, Karin y la tía Käte a quienes saludarás de mi parte de todo corazón. Y diles que mamá me ha escrito, y yo a ella, y que esto nos ha hecho muy felices. He podido ver también las deliciosas muñecas que te ha hecho, tienes que apreciarlas mucho, porque en cada punto hay un pensamiento de amor y de nostalgia por ti. 
Querido hijo, te tomo en mis brazos y te beso. Escribe alguna vez. (De Adam Kuckhoff - de 55 años, escritor, estudia matemática, derecho, economía y filosofía - a su pequeño, querido y gran hijo) (COMAS, 1975, p. 26).

Incluso os trechos apresentados e outros tantos além desses, chamame a atenção - e é o intuito ao apresentar este artigo - uma dimensão revelada no ato de escrever que é marcada pelos assuntos corriqueiros, cotidianos, pequenos recados, aconselhamentos, para os quais recorre-se a palavras e construções que se destacam pela linguagem singela, quase pura de intenções; e um incessante e insistente desejo de ser lembrado pondo em foco um exercício de si, empenhando-se em como se transporta ao outro.

Há a considerar-se que são altamente significativos os marcadores que remetem a uma face da história dos homens, em uma dada época, o da Segunda Guerra Mundial. Em acréscimo à história, Foucault escreve em A tecnologia política dos indivíduos que haveria "dificuldade de encontrar em toda a história carnificina comparável à da Segunda Guerra Mundial e, precisamente nesse período, nessa época, foram colocados em prática os grandes programas de proteção social, de saúde pública e de assistência médica" (FOUCAULT, 2006, p. 303).

Há, ainda, a relembrar essa face da história, que é registrada em livros, como os de Primo Levi, um sobrevivente. Da epígrafe - em itálico - posta na primeira página deste texto, escrito textualmente para manter viva a memória do horror, como um aviso lacerante para contradecir la cínica advertencia que las SS dirigían a sus víctimas: "Ninguno de vosotros quedará para contarlo, pero incluso si alguno lograra escapar, el mundo no le creería..." (apud MOREY, 2007, p. 364).

Assim como Thomas Mann recupera uma narração de Tolstoi apontando a sua sensibilidade para a intuição de acontecimentos futuros, no Prefacio do livro Cartas de condenados à muerte, assim também Morey recupera um dito de Pascal: Imagínese um número de hombres 
encadenados y condenados todos a muerte, vários de los cuales son degolados cada dia a la vista de los otros... bem logo Morey nos recupera os sentidos na afirmação de que Primo Levi não teve que imaginar tal situação; viu-a e viveu-a (MOREY, 2007, p. 365).

Essa face da história não podemos perder de vista. Com ela quase chegamos à morte. Muito próximo da morte. A leitura das palavras nos enredam num sentimento de angústia subjetiva que extrapola o sentir pessoal ao fazer transcorrer no íntimo o horror de certos fazeres de homens. É isto um homem?

\section{Uma estética da existência: apontamentos de leitura}

Da quase morte à vida. Aportados em quê? Uma leitura sensível das Cartas... aos poucos vai apontando uma possibilidade que se mostra pela poesia da vida tornada palavras, pela poesia das palavras tornada linguagem, pela linguagem tornada ponte, como o trecho apresentado à página 5 atribuído a Walter Kämpf e destinado aos pais; ou o trecho atribuído a Alfred Schmidt-Sas e destinado à sua esposa; ou o trecho atribuído a Adam Kuckhoff e destinado ao seu filho, ambos página 6. Lê-las, essas Cartas..., com sensibilidade, é apenas a ranhadura que mostra indícios da vida no concreto contexto da morte. Nos indícios da vida, é possível ler mais: é possível ler uma invenção da vida. Remete ao posicionamento de Foucault, frente à vida, ao referir-se à vida como obra de arte.

A referência à vida, pensada como obra de arte, inspira-se em um pequeno texto (entrevista) de Michel Foucault, intitulado Uma estética da existência. Dos seus estudos, que situa no domínio da história do pensamento, e remete de modo contundente à Antiguidade diz-nos, o autor, que

na Antiguidade, a vontade de ser um sujeito moral, a busca de uma ética da existência eram principalmente um esforço para afirmar a sua liberdade e para dar à sua própria vida uma certa forma na qual era possível se reconhecer, ser reconhecido pelos outros e na qual a própria posteridade podia encontrar um exemplo. 
Quanto à elaboração de sua própria vida como uma obra de arte pessoal, creio eu, embora obedecesse a cânones coletivos, ela estava no centro da experiência moral, da vontade de moral na Antiguidade... (FOUCAULT, 2006, p. 290).

O que chama a atenção nesse trecho, pinçado entre tantas preciosidades do pensamento do autor, é a possibilidade viva pela qual podemos nos enveredar rumo à elaboração de uma vida pessoal que possa ser pensada como uma obra de arte, porque traz um sentido de construção -ética e de vontade moral - na liberdade, porque carrega singularidades em meio a cânones coletivos - se nos perguntarmos a quê vêm alguns materiais específicos, as Cartas... por exemplo, transformadas em livros, porque considera-se a arte de escrever como um modo de inscrever-se e ser reconhecido e porque demarca uma efervescente e potente fronteira de ser sensível pensante, quando o tema é liberdade de pensamento.

Celda 411, 4 de abril de 1945.... Sé que eres una mujer fuerte y que te resignarás, pero no debes limitarse a resignarte, debes también tomar conciencia. No soy más que una pequeña cosa, mi nombre será pronto olvidado, pero la idea, la vida y la inspiración que me embargaban continuarán viviendo. Las encontrarás en toda parte, sobre los árboles en primavera, en los hombres por el camino, en una breve y dulce sonrisa. Encontrarás lo que tuvo un valor para mí, lo amarás y no me olvidarás. Creceré y me haré maduro, viviré en vosotros, cuyos corazones he ocupado, y vosotros continuaréis viviendo, porque tenéis que saber que me encuentro delante de vosotros y no detrás, como quizás estabas inclinada a creer. He elegido un camino del que no me arrepiento, nunca he estado por debajo de todo cuando había en mi corazón, y ahora me parece ver cierta correlación. No soy viejo, no debería morir, y sin embrago me parece algo natural y sencillo. Tan sólo es el modo brusco lo que me asusta en un primer momento. El tiempo es breve, los pensamientos son muchos. No comprendo por qué, pero mi espíritu está tranquilo. Quisiera haber sido un Sócrates, pero me ha faltado el público. Siento su misma calma, y quisiera que os dieseis perfecta cuenta de ello. 
En el fondo es bastante extraño estar sentado ocupado en redactar este documento para la vida. Cada palabra impresa, no puede ser modificada, nunca cambiada.

...Nuestro país tiende hacia una gran meta, algo a lo que también el pequeño campesino aspirará, mientras siente con alegría que su trabajo y su lucha han hecho suyo ese "algo".

Finalmente, está la que es mía. Hacedle comprender que las estrellas brillan aún y que yo no era una piedra miliaria. Ayúdala, ahora podrá ser muy feliz. Apresuradamente, tu hijo mayor y único. (De Kim Malthe-Bruun - de 21 años, marino - a su madre) (COMAS, 1975, p. 113-115)

Carta a carta, o leitor, a leitora, é posto(a) lado a lado com o(a) destinatário(a) fazendo-se interlocutor(a) privilegiado(a). A cada leitura, parece estabelecer-se um vínculo fronteiriço e indissolúvel entre a vida (por um fio), a morte (como certeza) e a vida (trazida pelas formas vivas da linguagem).

O que torna a linguagem vida: seria a escrita, o objeto? Seria a ponte que interconecta autor/a e leitor/a para além da forma, do contexto, do tempo, do espaço? Seria a inerência do ato de escrever ao sujeito, aquele que escreve e aquele que lê, inerência essa que acontece nos umbrais do pensamento, disparada pela linguagem escrita e que não cessa?

\section{Referências}

BAJTÍN, M. Hacia una filosofia del acto ético. De los borradores y otros escritos. Tradução do russo por Tatiana Bubnova. Rubí (Barcelona, ES): Anthropos; San Juan: Universidad de Puerto Rico, 1997.

BAKHTIN, M. Os gêneros do discurso. In: verbal. São Paulo: Martins Fontes, 2003. p. 277-326. . Estética da criação 
BENJAMIN, W. Magia e técnica, arte e politica. Ensaios sobre literatura e história da cultura. 3. ed., Tradução de Sérgio Paulo Rouanet. São Paulo: Brasiliense, 1987.

COMAS, R. Cartas de condenados a muerte. Víctimas del nazismo. Barcelona: Editorial Laia, 1975. Edição original Lettere di condannati a morte della resistenza europea. 2. ed., Tradução do italiano por Jaume Reig. Einaudi Editore, 1975.

FOUCAULT, M. Ética, sexualidade, política. Organização de Manoel B. Motta. Tradução de. de Elisa Monteiro e Inês A. D. Barbosa. Rio de Janeiro: Forense Universitária, 2006.

LARROSA, J. Narrativa, identidad y desidentificación. In: . $L a$ experiencia de la lectura. Estudios sobre literatura y formación. Barcelona: Alertes, 1996.

LARROSA, J. Nietzsche \& a educação. Belo Horizonte: Autêntica, 2002.

MOREY, M. La prosa del superviviente. In: . Pequeñas doctrinas de soledad. Madrid, ES: Sexto Piso España, S.L., 2007.

NIETZSCHE, F. A gaia ciência. Tradução, notas e posfácio de Paulo C. Souza. São Paulo: Companhia das Letras, 2002.

NIETZSCHE, F. Aurora. Tradução, notas e posfácio de Paulo C. Souza. São Paulo: Companhia das Letras, 2004.

RANCIÈRE, J. Políticas da escrita. Tradução de Raquel Ramalhete, Laís Eleonora Vilanova, Lígia Vassalo e Eloísa de Araújo Ribeiro. Rio de Janeiro: Ed. 34, 1995.

Data de registro: 04/11/2013

Data de aceite: 21/09/2016 